\title{
Temperature Monitoring System for Baby Incubator Based on Visual Basic
}

\author{
Abdul Latif ${ }^{1}$, Afif Zuhri Arfianto ${ }^{2}$, Joessianto Eko Poetro ${ }^{3}$, Thanh Nguyen Phong ${ }^{4}$, Elsayed T.Helmy \\ ${ }^{1}$ Universitas Islam Sultan Agung, Semarang, Indonesia \\ ${ }^{2,3}$ Politeknik Perkapalan Negeri Surabaya, Surabaya, Indonesia \\ ${ }^{4}$ Director, Department of Project Management, Ho Chi MinhCity Open University, Vietnam \\ ${ }^{5}$ National Institute of oceanography and fisheries, Alexandria \\ 4bdullatif.u.m.y@gmail.com, afifzuhri@ieee.org, joessianto@ppns.ac.id,phong.nt@ou.edu.vn, \\ stalaat41@gmail.com
}

\begin{abstract}
An incubator room is designed to keep the temperature warm so that the baby feels comfortable. A temperature monitor system for the incubator room placed separately from where the officer works is a hassle and a waste of time. The research aimed to design a temperature detector for an infant incubator that had a constant temperature and was monitored directly in a staff room. An LM35 sensor as a temperature detector was used in the design and installed in a $100 \times 80 \mathrm{~cm}$ room. The detected temperature was displayed on the LCD and computer in the staff room. The temperature $\left({ }^{\circ} \mathrm{C}\right)$ was converted into an ADC (Analog Digital to Converter) value by an Arduino Uno microcontroller. Several LM35 sensors were mounted in rooms to detect the temperature. The LM 35 sensor was used by considering that it could be calibrated directly in the Celsius scale, a linear scale factor of $10 \mathrm{mV} /{ }^{\circ} \mathrm{C}$, and it had a temperature range between $-55^{\circ} \mathrm{C}$ and $150^{\circ} \mathrm{C}$.
\end{abstract}

Keywords - temperature sensor, humidity sensor, incubator, temperature sensor

\section{INTRODUCTION}

LM35 sensor can detect temperatures accurately because it has a very high level of accuracy. The temperature results detected by the sensor can be directly converted by Arduino Uno from the analog to digital signals and then displayed on a computer, directly monitored by nurses/officers. When the temperature exceeds the limit, the heater will turn off, but if it is below the limit, the heater will turn on. Thus, the constant temperature can be obtained.

Several previous studies have conducted research on temperature. An embedded based remote monitoring station for live streaming of temperature and humidity was investigated by Halder and Sivakumar [1]. Monitoring of ZigBee-based Server Room Temperature and Humidity using Thermal Imaging was investigated by Yumang [2]. Remote Condition Monitoring Real-Time Light Intensity and Temperature Data was studied by [3]. Low power wireless temperature sensors for health monitoring were investigated by Radoi, Dobrescu and Post [4]. The design and improvement of the freshwater crayfish breeding system by controlling water temperature and monitoring $\mathrm{pH}$ through cloud system services was investigated by Photsathian, Suttikul and Tangsrirat [5]. The design and development of a monitoring system for air temperature and relative humidity with a web server based on the AVR processor was investigated by Simic [6]. Vacuum packaging and semi-fan chips for wireless temperature monitoring in industrial applications were investigated by Tijero [7]. The research of SAW-based Online Temperature Monitoring System for Intelligent Circuit Breaker was researched by Ma [8]. The design and implementation of the infrared rotary kiln shell temperature monitoring system was investigated by Liu [9]. A sophisticated battery model for simulating WSN in a temperature variation environment was investigated by Rodrigues [10].

Wireless temperature and humidity monitoring using a sensor array was investigated by Noushad [11]. Case study: The control and multivariable design of level and temperature via arduino via decoupling control loop was investigated by Machado [12]. Arduino-based temperature and humidity control for condensation on engineered surfaces with wet capability was investigated by Gupta [13]. Temperature Control System for Accelerated Aging Tests on Printed Circuit Boards was investigated by LITA [14]. The Artificial Immunity Negative Selection Algorithm for Controlling Water Temperature in Outlet Chamber was investigated by Marciniak, Wawryn and Widulinski [15]. The Fuzzy Logic Control of Humidity and Temperature in Neonatal Incubator was studied by Ili Flores [16]. Temperature and Humidity Control of Fuzzy Greenhouses based on Arduino was investigated by Benyezza [17]. The design of a constant temperature boiler system with fuzzy control and remote monitoring functions was investigated by Chunli Jiang [18]. The design of a server room temperature and humidity control system using a microcontroller-based fuzzy logic was investigated by Purwanto, Utami and Pramono [19]. Control of Solar Water Pumping Systems Using Low Cost ESP32 Microcontroller was investigated by Bipasha Biswas and Tariq Iqbal [20].

The prototype of an ultraviolet light dryer using ATMega8 was studied by Tunggal [21]. The microcontroller-based safety system was studied by Pawlenka and Skuta [22]. The development of smart quail egg incubators for microcontroller-based hatching systems and the Internet of Things (IoT) was researched by Sanjaya [23]. Microcontroller breeding of smart goldfish eggs was studied by Mandala, Sumaryo and Estananto [24]. The design and development of elderly assistance systems using mobile applications and an 8bit microcontroller was studied by Romero de Jesus, Ibarra Bonilla and Quinones Novelo [25]. Thermoelectric module 
heat sink design for cooling systems was investigated by Monel, Kamal and Omar [26]. Using Proteus to Support Engineering Student Learning: A Case Study of Microcontroller-Based Sensors was researched by Asparuhova, Shehova and Lyubomirov [27]. The adaptive temperature control design of all coefficients based on the characteristic model was investigated by Jiang, Liu and Han [28]. The process of milling and automatic coffee making with the NUC140 microcontroller was investigated by [29]. Data Storage-Based Heart and Body Temperature Measurement Devices was investigated by Wijaya [30].

From this background, this paper applies the LM35 temperature sensor for temperature monitoring at the incubator.The results of the temperature measurement detected in the baby incubator can be seen directly on the computer screen without checking directly to the incubator room. The results of this study are expected to facilitate nurses/officers to monitor the temperature in the baby incubator continuously.

\section{METHOD}

The first step to designing a temperature monitor system was making a block diagram displaying the stages of the design process. Figure 1 shows the designed system. It can be further developed.

The system reduced the time in checking the temperature in the incubator room, providing continuous information about the temperature. The temperature changes detected by the LM35 sensor equipped with a thermometer were recorded. The software design used CodeVisionAVR programming for Arduino Uno and PC interface programming using Microsoft Visual Basic 6.

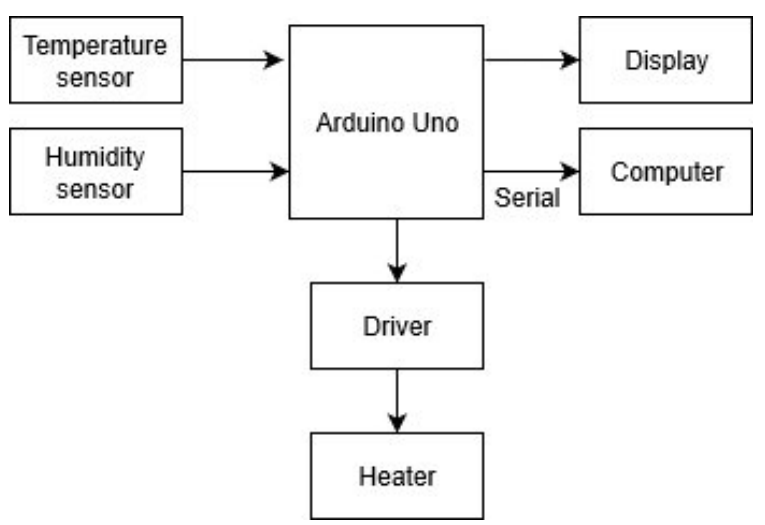

Fig. 1. PID system block diagram

\section{IMPLEMENTATION}

The system design consisted of several parts, namely hardware electrical devices, firmware, and software interfaces. The electrical module consisted of Arduino Uno Board, and temperature and humidity sensors. A firmware was made as a working processor microcontroller, and a software interface was made for display.

\section{A. Temperature sensor test}

The LM35 sensor has high accuracy and ease of design, compared to other temperature sensors. It has three pins, namely, pin 1 , or Vin as the voltage source, pin 2, or middle pin, or Vout as the output voltage, and pin 3, as the ground.
Figure 2 displays the LM35 sensor schematic diagram.

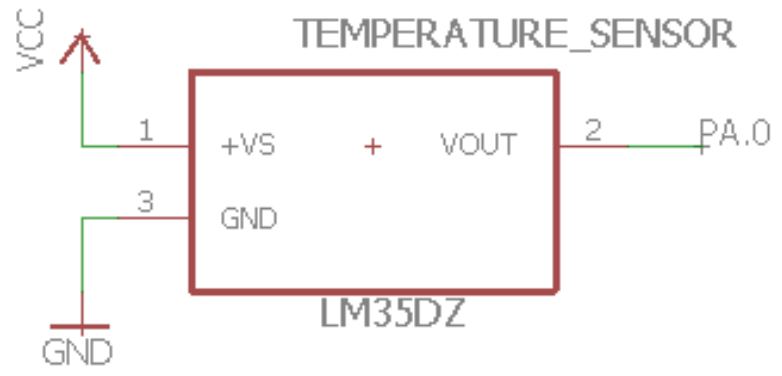

Fig. 2. LM 35 sensor schematic diagram.

The comparison between the temperature results detected by the LM35 sensor and a thermometer as a comparative instrument is presented in table 1 . The table shows that the measurement results obtained are quite good, with an effective temperature of $31{ }^{\circ} \mathrm{C}$ to $36^{\circ} \mathrm{C}$.

TABLE I. TEMPERATURE SENSOR OUTPUT COMPARISON

\begin{tabular}{|r|c|c|}
\hline \multicolumn{1}{|l|}{ No } & Sensor LM35 Output $\left({ }^{\circ} \mathbf{C}\right)$ & Standard Thermometer Output $\left({ }^{\circ} \mathbf{C}\right)$ \\
\hline 1 & $\mathbf{2 9}$ & $\mathbf{3 0}$ \\
\hline 2 & $\mathbf{3 0}$ & $\mathbf{3 0}$ \\
\hline 3 & $\mathbf{3 1}$ & $\mathbf{3 1}$ \\
\hline 4 & $\mathbf{3 2}$ & $\mathbf{3 1}$ \\
\hline 5 & $\mathbf{3 3}$ & $\mathbf{3 2}$ \\
\hline 6 & $\mathbf{3 4}$ & $\mathbf{3 4}$ \\
\hline
\end{tabular}

\section{B. Arduino programming}

An Arduino Uno is a microcontroller board based on ATmega 328P with the specifications of 14 digital inputs/outputs, six as PWM output, six analog inputs, $16 \mathrm{MHz}$ Crystal oscillator, USB connector power jack, ICSP header, and reset button.

The system started by connecting the Arduino to the computer using a USB cable or by providing an AC voltage to the DC adapter or battery. It used the Atmega8U2 microcontroller programmed as the USB-to-serial converter, and an IHD162A Liquid Crystal Display, capable of displaying 16 columns and two rows (16x2) characters.

A buzzer worked to change the electrical vibration into sound vibration as a reminder to officers. It consisted of several coils mounted on a diaphragm element producing electromagnetic currents. Since the coil was mounted on the diaphragm, each movement of the coil moved the diaphragm back and forth to make the air vibrate producing sound, used as an alarm.

\section{Graphical User Interface (GUI)}

Detected temperature results were displayed on the LCD and the computer screen. The LCD was attached to the microcontroller because it had a small dimension and displayed better graphic characters. Figure 3 displays the Graphical User Interface with Visual Basic 6.0. The display of temperature results was necessary to make so that the officer could monitor thE TEMPERATURE OF THE INCUBATOR. It can be seen that there are 3 buttons to run the monitoring program, namely the star, stop and exit buttons. The software was created after finishing the hardware. Visual Basic was a tool for building applications in a Windows environment. Visual Basic used the Visual approach to design user interfaces for developing applications and Basic language dialects for 
coding. The visual basic 6.0 interface displayed the temperature results using the LM35 sensor on the computer.

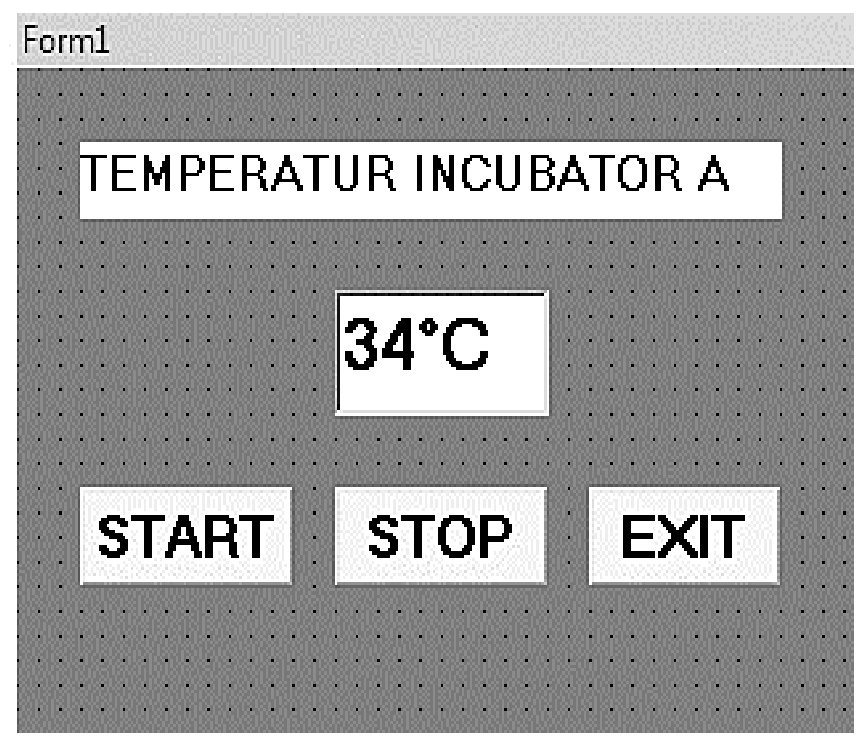

Fig. 3. GUI with Visual Basic 6.0.

Table 2 presents the percentage of relatively small errors, ranging from 0 to 0.3 It proved that the measurement results have high accuracy in monitoring and detecting the temperature in the baby incubator. . The system can monitor and detect the temperature in the baby incubator room. The temperature results detected by the LM35 sensor could be displayed on the computer in the staff room or a $16 \times 2$ LCD in the baby incubator room.

TABLE II. TEST RESULT OF OVERALL SENSOR OUTPUT

\begin{tabular}{|r|c|c|c|}
\hline \multicolumn{1}{l|}{ No } & Standard Thermometer Output $\left({ }^{\mathbf{}} \mathbf{C}\right)$ & Displayed $\left({ }^{\circ} \mathbf{C}\right)$ & Error \\
\hline 1 & 2 & 2.2 & 0.2 \\
\hline 2 & 5 & 5.3 & 0.3 \\
\hline 3 & 10 & 10.2 & 0.3 \\
\hline 4 & 15 & 15.2 & 0.2 \\
\hline 5 & 20 & 20.3 & 0.3 \\
\hline 6 & 25 & 25.0 & 0 \\
\hline 7 & 30 & 30.1 & 0.1 \\
\hline 8 & 35 & 35.2 & 0.2 \\
\hline 9 & 40 & 40.1 & 0.1 \\
\hline 10 & 45 & 45.0 & 0 \\
\hline
\end{tabular}

\section{CONCLUSION}

Based on the results of the research, it can be concluded that the temperature monitor system has worked properly. The system can monitor and detect the temperature in the baby incubator room to be displayed on a computer screen or an LCD in the staff room, and the results are satisfactory. The temperature detected by the LM35 sensor can be displayed either on the computer in the staff room or the 16x2 LCD in the baby incubator room. The system provides information continuously.

\section{REFERENCES}

[1] S. Halder and G. Sivakumar, "Embedded based remote monitoring station for live streaming of temperature and humidity," in 2017 International Conference on Electrical, Electronics, Communication, Computer, and Optimization Techniques (ICEECCOT), 2017, pp. 284-287.
[2] A. N. Yumang, C. C. Paglinawan, M. M. Sejera, A. S. Lazam, J. C. Pagtakhan, and J. S. B. Santos, "ZigBee Based Monitoring of Temperature and Humidity of Server Rooms using Thermal Imaging," in 2016 6th IEEE International Conference on Control System, Computing and Engineering (ICCSCE), 2016, no. November, pp. 452454.

[3] N. Khera, H. Gill, G. Dodwani, N. Celly, and S. Singh, "Remote Condition Monitoring of Real-Time Light Intensity and Temperature Data," in 2015 Second International Conference on Advances in Computing and Communication Engineering, 2015, vol. 1, pp. 3-6.

[4] I. Radoi, L. Dobrescu, and S. V. Pasca, "Low-power wireless temperature sensor for health monitoring," in 2017 10th International Symposium on Advanced Topics in Electrical Engineering (ATEE), 2017, pp. 254-257.

[5] T. Photsathian, T. Suttikul, and W. Tangsrirat, "Design and improvement of wireless crayfish breeding system by controlling water temperature and monitoring $\mathrm{pH}$ via cloud system services," in $20183 \mathrm{rd}$ International Conference on Control and Robotics Engineering (ICCRE), 2018, pp. 205-208.

[6] M. Simic, "Design and development of air temperature and relative humidity monitoring system with AVR processor based web server," in 2014 International Conference and Exposition on Electrical and Power Engineering (EPE), 2014, no. 289481, pp. 038-041.

[7] M. Tijero et al., "Vacuum packaging and semipassive chips for wireless temperature monitoring in industrial applications," in 2017 IEEE SENSORS, 2017, vol. 2017-Decem, no. 4, pp. 1-3.

[8] J. Ma, X. Chen, Y. Tan, T. Zhao, C. Li, and B. Yu, "Research on Online Temperature Monitoring System Based on SAW for Intelligent Circuit Breaker," in 2017 4th International Conference on Information Science and Control Engineering (ICISCE), 2017, pp. 1168-1170.

[9] T. Liu, Q. Zhang, G. Li, Z. Ma, and M. Zhang, "Design and implementation of the temperature monitoring system of infrared rotary kiln shell," in 2017 12th IEEE Conference on Industrial Electronics and Applications (ICIEA), 2017, vol. 2018-Febru, pp. 253257.

[10] L. Rodrigues, E. Leao, C. Montez, R. Moraes, P. Portugal, and F. Vasques, "An Advanced Battery Model for WSN Simulation in Environments With Temperature Variations," IEEE Sens. J., vol. 18, no. 19, pp. 8179-8191, Oct. 2018.

[11] M. Noushad, B. Tauheed, S. A. Khan, and M. A. Khan, "Wireless monitoring of temperature and humidity using sensor array," in 2015 Annual IEEE India Conference (INDICON), 2015, pp. 1-5.

[12] M. M. Machado, A. J. Carvalho, M. F. Santos, and J. R. de Carvalho, "Case study: Level and temperature multivariable control and design via arduino through control loop decoupling," in 2018 19th International Carpathian Control Conference (ICCC), 2018, pp. 247252.

[13] R. Gupta, C. Das, A. Roy, R. Ganguly, and A. Datta, "Arduino based temperature and humidity control for condensation on wettability engineered surfaces," in 2018 Emerging Trends in Electronic Devices and Computational Techniques (EDCT), 2018, pp. 1-6.

[14] A. I. LITA, D. A. VISAN, L. Mihai IONESCU, and A. G. MAZARE, "Temperature Control System for Accelerated Aging Tests on Printed Circuit Boards," in 2018 10th International Conference on Electronics, Computers and Artificial Intelligence (ECAI), 2018, pp. 1-4.

[15] J. Marciniak, K. Wawryn, and P. Widulinski, "An Artificial Immune Negative Selection Algorithm to Control Water Temperature in the Outlet of the Chamber," in 2018 International Conference on Signals and Electronic Systems (ICSES), 2018, pp. 236-241.

[16] S. A. Ili Flores, H. J. Konno, A. M. Massafra, and L. Schiaffino, "Simultaneous Humidity and Temperature Fuzzy Logic Control in Neonatal Incubators," in 2018 Argentine Conference on Automatic Control (AADECA), 2018, pp. 1-6.

[17] H. Benyezza, M. Bouhedda, M. C. Zerhouni, M. Boudjemaa, and S. Abu Dura, "Fuzzy Greenhouse Temperature and Humidity Control based on Arduino," in 2018 International Conference on Applied Smart Systems (ICASS), 2018, no. November, pp. 1-6.

[18] Chunli Jiang, Zhenglin Li, Yang Zhou, Xiaohu Qin, and Zeshuang Zhao, "Design of constant temperature boiler system with fuzzy control and remote monitoring function," in 2015 IEEE International Conference on Communication Problem-Solving (ICCP), 2015, pp. 38-42.

[19] F. H. Purwanto, E. Utami, and E. Pramono, "Design of server room temperature and humidity control system using fuzzy logic based on 
microcontroller," in 2018 International Conference on Information and Communications Technology (ICOIACT), 2018, vol. 2018-Janua, pp. 390-395.

[20] S. Bipasha Biswas and M. Tariq Iqbal, "Solar Water Pumping System Control Using a Low Cost ESP32 Microcontroller," in 2018 IEEE Canadian Conference on Electrical \& Computer Engineering (CCECE), 2018, vol. 2018-May, pp. 1-5.

[21] T. P. Tunggal, A. W. Apriandi, J. E. Poetro, E. T.Helmy, and F. Waseel, "Prototype of Hand Dryer with Ultraviolet Light Using ATMega8," J. Robot. Control, vol. 1, no. 1, pp. 7-10, 2020.

[22] T. Pawlenka and J. Skuta, "Security system based on microcontrollers," in 2018 19th International Carpathian Control Conference (ICCC), 2018, pp. 344-347.

[23] W. S. M. Sanjaya et al., "The development of quail eggs smart incubator for hatching system based on microcontroller and Internet of Things (IoT)," in 2018 International Conference on Information and Communications Technology (ICOIACT), 2018, vol. 2018-Janua, pp. 407-411.

[24] B. S. Mandala, S. Sumaryo, and Estananto, "Smart Gold Fish Eggs Nursery with Microcontroller," in 2018 International Symposium on Electronics and Smart Devices (ISESD), 2018, pp. 1-6.

[25] A. M. Romero de Jesus, M. N. Ibarra Bonilla, and F. J. Quinones Novelo, "Design and development of an elderly assistance system using a mobile application and an 8-bit microcontroller," in 2018 15th
International Conference on Electrical Engineering, Computing Science and Automatic Control (CCE), 2018, pp. 1-4.

[26] M. A. M. Monel, M. M. Kamal, and M. H. Omar, "Heat sink design of Thermoelectric Module for cooling system," in 2016 6th IEEE International Conference on Control System, Computing and Engineering (ICCSCE), 2016, no. November, pp. 184-188.

[27] K. Asparuhova, D. Shehova, and S. Lyubomirov, "Using Proteus to Support Engineering Student Learning: Microcontroller-Driven Sensors Case Study," in 2018 IEEE XXVII International Scientific Conference Electronics - ET, 2018, pp. 1-4.

[28] W. Jiang, Y. Liu, and J. Han, "The design of the all-coefficient adaptive temperature controller based on characteristic model," in 2017 36th Chinese Control Conference (CCC), 2017, pp. 6547-6551.

[29] F. T. Boro, I. Riyanto, and K. Adiyarta, "Automatic coffee grinding and brewing process with NUC140 microcontroller," in 2017 3rd International Conference on Science in Information Technology (ICSITech), 2017, pp. 537-540.

[30] N. H. Wijaya, A. G. Alvian, A. Z. Arfianto, J. E. Poetro, and F. Waseel, "Data Storage Based Heart and Body Temperature Measurement Device," J. Robot. Control, vol. 1, no. 1, pp. 11-14, 2020. 